Canadian Journal of Family and Youth, 10(2), 2018, pp 7-27

ISSN 1718-9748 (C) University of Alberta

http://ejournals.library.ualberta.ca/index/php/cjfy

\title{
Towards a Decolonizing Pedagogy of Solidarity
}

\author{
Daniela Navia
}

\begin{abstract}
In this paper, I discuss how the (dis)placement of Indigenous youth in child welfare can be better understood through youth's stories, voices and artwork. I will describe my approach and outline how the Uncovering Colonial Legacies research project developed, seeking to amplify the conversation about ongoing settler colonialism.
\end{abstract}

Daniela Navia is a Research Consultant with the Alberta Foundation for the Arts. Her research interests involve community engagement, collaborative ethnography, decolonization, and visual anthropology. Major publications include: Navia, D, Henderson, R, First Charger, L. (In Press) Uncovering Colonial Legacies: Voices of Indigenous Youth on Child Welfare (dis)Placements. Anthropology \& Education Quarterly; Navia, D. (2015) Uncovering Colonial Legacies: Voices of Indigenous Youth in Child Welfare (dis)Placements. Electronic Theses http://theses.ucalgary.ca/handle/11023/2479; and Logie, CH, Navia, D, Loutfy, MR. (2014) Correlates of a Lifetime History of Sexually Transmitted Infections among Women who have Sex with Women in Toronto, Canada: Results from a Cross-sectional Internet-based survey. Sexually Transmitted Infections, sextrans-2014. 
Navia

\section{Introduction}

At the opening of the Uncovering Colonial Legacies art exhibit as part of the This Is My

City festival, youth collaborator Sarah Scout (Figure 1) described how she became involved in an exhibit about the experiences of Indigenous youth with the child welfare system:

When I was asked if I wanted to be part of this exhibit my immediate response was one of defense and a little fear. However, when it was explained to me that the intent of this exhibit was not inspired to promote child welfare but to "Uncover [its] Colonial Legacies," in my heart I knew there might be room not only for me, but a safe space for my art and voice to join with others who have survived and are surviving "child welfare (dis)Placement.” —Sarah Scout, youth collaborator, Calgary, April 2015.

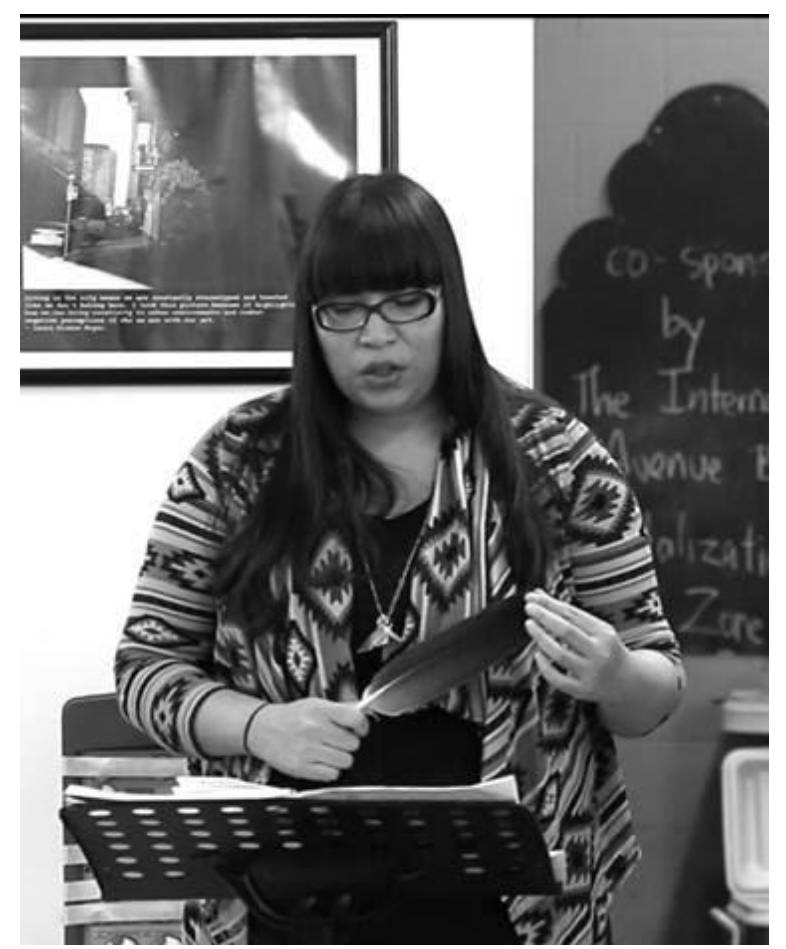

Figure 1. Sarah Scout, youth collaborator, at Uncovering Colonial Legacies exhibit opening for This Is My City arts festival. Photo by Deloria Many Grey Horses.

Sarah explains how she was hesitant to participate until she found out that the purpose of the exhibit was to support critical Indigenous youth voices. She references the title in particular, which she later indicated, struck a very important chord with her through its framing of child welfare as a form of displacement linked to ongoing colonialism. This was a theme that guided the Uncovering Colonial Legacies project, a collaborative endeavor with youth that enabled 
critical discourses to emerge that are not often visible or encouraged. In this paper, I discuss how the placement of Indigenous youth in child welfare can be better understood through critical research grounded in youth’s stories, voices, and artwork. I will describe the research approach and outline how the Uncovering Colonial Legacies project developed, seeking to amplify the conversation about ongoing settler colonialism.

Representation of racialized peoples in hegemonic discourse has long been the subject of critical scholarly analysis (Asad, 1973). Historically, anthropological studies on Indigenous peoples have focused on culture and often reified depictions of timeless traditions and remnants of the past, fetishizing Indigenous peoples, and effectively excluding an analysis of how they have been impacted by and resisted colonialism (for critical analysis of the scholarship see Deloria, 1988; Simpson, 2011, 2014; Wolf, 2010). As a result of anti-colonial struggles around the world, post-colonial and subaltern studies have generated knowledge on the impact of colonization and possibilities to challenge and undermine empire (Comaroff \& Comaroff, 2003; Spivak, 2003). Indigenous scholars have produced research that is critical of broader power structures in (re)shaping Indigenous cultures and includes Indigenous voices and varied experiences of their bearers (Hunt, 2014; Simpson, 2014, p. 163). These efforts have helped to reconceptualize Indigenous knowledge as “relational and alive” (Hunt, 2014, p. 31) and as a product of ongoing historical processes. Indigenous scholars speaking for themselves interrupt portraits of "timelessness, procedure and function that dominate representation of their past, and sometimes their present” (Simpson, 2014, p. 97).

Indigenous scholars have made a major contribution by advancing “decolonizing” as a research praxis, which entails purposeful acknowledgement of how inequality shapes experiences and a commitment to reciprocal relationships between academics and partnering 
communities (Smith, 1999; Wilson, 2008). Decolonizing research requires the researcher to step beyond the position of 'expert' in order to also be a witness or listener and to support systemic change. Scholars have argued that decolonization has often been misused to describe a process to expand settler thinking and recognize Indigenous peoples without challenging colonial processes. For example, Kwakwaka'wakw scholar Sarah Hunt warns that through a lack of Indigenous scholars in Geography, there is a danger that decolonization praxis will be an extension of past discourses of how to engage with the other (2014, p. 31). The essay “Decolonization is Not a Metaphor” by Eve Tuck and Wayne Yang examines how decolonizing has been misappropriated primarily by non-Indigenous people, in ways that obscure the dynamics of colonization (Tuck \& Yang, 2012). The co-authors argue that reducing decolonization to a metaphor enables "settler moves to innocence," attempting to reconcile settler guilt and complicity without seeking to challenge unfair social structures (2012, p. 1).

As a Mestiza Latina migrant, I am pursuing research with Indigenous peoples under what Ruben Gatztambide-Fernandez describes as a pedagogy of decolonizing solidarity (2012). ${ }^{1}$ I am interested in moving away from "explaining or enhancing existing social arrangements, seeking instead to challenge such arrangements and their implied colonial logic” (GatztambideFernandez, 2012, p. 49). Therefore, I am challenging settler colonialism, taking the experience of colonization and the racialized other as a point of departure. My experiences with migrating from Colombia and discrimination while living in Canada serve as a strong foundation in which I ground myself in this research. I have been inspired by the work of No One is Illegal, an activist group that frames migrant issues as inextricably connected to Indigenous issues under the banner

\footnotetext{
${ }^{1}$ Henry Giroux defines pedagogy as linking "the notions of schooling and the broader category of education to a more substantive struggle for a radical democratic society” (1992, p.28). In the context of postcolonial and critical scholarship, pedagogy requires seeking to challenge and dismantle what Aruna Srivastava describes as relationships within the academy "that are identical to and indeed a consequence of the imperialistic impulse" (1995, p.17).
} 
of border imperialism, which regulates the claims to land and movement of groups through borders (Walia, 2013).

The encounter between Indigenous and diasporic communities presents opportunities for valuable solidarity as well as challenges. Decolonization can be regarded as a "common interest" that unites Indigenous peoples and other racialized populations (Gatztambide-Fernandez, 2012, p. 61). However, distinct histories of oppression and resistance often complicate the relationship between these two groups as migrants are complicit in the enactment of settler colonial violence towards Indigenous peoples in Canada, and often also in their countries of origin. Andrea Smith argues that within the logic of white supremacy, reasonable solutions to the problems of some marginalized groups compound the subjugation of others (Smith, 2006). For example, for many migrants, inclusion and acceptance into the Canadian state has been construed as a potential solution to racial inequality. This perspective leaves the colonial relationship between the state and Indigenous peoples unchallenged. Therefore, in order to pursue a pedagogy of decolonizing solidarity, migrants must acknowledge that we are not innocent in the oppression of Indigenous peoples and should work to support of Indigenous political action.

I have been guided in this project by a desire to resist settler colonialism and support the political struggles of Indigenous peoples. Academic critiques of decolonization discourses argue that metaphorical colonization, or a decolonization of settler mindsets is inadequate unless it supports Indigenous struggles for self-determination and sovereignty (Tuck \& Yang, 2012). In research, this presents a challenge for non-Indigenous people to alter their praxis to better support Indigenous voices and redistribute power. In this regard, collaborative approaches may be useful to undermine the colonial structures that have dictated depictions of Indigenous lives and knowledge in academia. 
Navia

\section{A Collaborative Approach}

Scholars have stressed the need to support Indigenous youth's voices as part of challenging hegemonic assumptions about “problem” individuals (Menzies, 2008; Mutua \& and Swadener, 2004; Reid, 2005; Smith, 1999). The voices of youth in the child welfare system, have been largely excluded from research. With this inquiry, I seek to challenge notions of youth as categories to be spoken for, posing instead that they are recognized as actors in their social world who are capable of communicating complex narratives of the issues that affect them (Carreire, 2008; Chapman et al., 2004; Gray, 2011). A collaborative approach is particularly useful to magnify and support youth voices.

The El Dorado Task Force of the American Anthropological Association defines collaborative research as "side by side work of all parties in a mutually beneficial research program (Lassiter 2005, p. ix). Collaborative approaches have been developed as a way to address some of the issues with appropriation and misuse of knowledge in Anthropology and incorporate valuable perspectives and feedback from community members represented in texts (Lassiter, 2005). Acknowledging research participants as knowledge keepers and collaborators is a beneficial strategy to mitigate the risk of misrepresentation and encourage critical dialogue (Jahnke \& Gillies, 2012; Mitchell, 2006). Collaborative ethnography is an iterative process where different groups deliberately shape the research and final products to benefit to those involved (Marcus \& Fischer, 1999). Within Indigenous contexts, collaborative ethnography is increasingly the norm; however, it is debated whether Anthropology is making significant strides to reconcile the power imbalances in ethnographic knowledge production (Lassiter, 2005). Dakota scholar Vine Deloria Jr.’s critique that anthropology endures as a “deeply colonial academic discipline” (1997, p. 211) remains relevant, pointing to an ongoing hierarchical 
relationship between the academy and Indigenous communities that persists despite attempts to engage different voices. I wish, as Sarah Ahmed asserts, not to describe Indigenous peoples, but to describe the encounters in which I am faced with them and to not "hold them in place... into a theme, concept or thing” (2000, p. 145). Yet I recognize that as a non-Indigenous scholar, my engagement with Indigenous voices is nonetheless a hierarchical process (Ahmed, 2000).

A focus on Indigenous voices is a form of ethnographic refusal, or challenging the idea that entire cultures can be known or spoken for (Simpson, 2011). Audra Simpson advocates for segregating culture into a variety of narratives rather than generating a comprehensive “official story” and examining the social contexts that produce narratives (2014, p. 97). I am interested in re-appropriating concepts like culture and identity “in ways that lead the reader's gaze back to the social and economic injustices neglected and deflected” (Wong, 2011, p. 159). I employ a “post-cultural” approach that involves a direct engagement with and critique of culture as an "ever changing part of how we engage with each other across difference. Something that we do and something that is done to us” (Gatzatambide-Fernandez, 2012). In order to examine Indigenous cultures, one must draw on multiple mediums in which Indigenous peoples create Indigenous knowledge. In the following section, I examine the role of storytelling and art as mediums for challenging colonial structures.

\section{Indigenous Art and Storytelling}

Storytelling and art are important vehicles in production of Indigenous knowledge. Stories and storytelling are nuanced ways of knowing that are produced within relational networks of meaning (Kovack, 2010, 2008; Tuhiwai-Smith, 1999; see also Spring and Fox in this volume). Anthropological perspectives on storytelling suggest that stories are adaptive means for talking about and making sense of social change (Cruikshank, 2000; Kane, 2010;). 
Navia

Storytelling can also generate opportunities for resistance and change (Beavon, Voyageur, \& Newhouse, 2011; Hedican, 2008). Sium and Ritskes describe Indigenous storytelling as “decolonization theory in its most natural form” (2013, p. ii). It is a way to ground the material realities of those who have been impacted by and resisted colonialism and a way to recognize their subjectivities as intellectually and politically valid (Sium and Ritskes, 2013, p. iii-iv). Therefore, Indigenous storytelling is inherently political and should be recognized as a form of creative rebellion, beyond liberal notions of storytelling as a "multicultural 'show and tell'” (Sium \& Ritskes, 2013, p. v).

Within Indigenous storytelling traditions visual art is an important medium to communicate Indigeneity and decolonization. Kanyen’kehaka artist Greg Hill describes Indigenous art as "aesthetic sovereignty” that allows Indigenous peoples to express their perspectives on heritage and ongoing colonization (2013, p. 137). The power of Indigenous art to uncover and resist colonial legacies of the child welfare system is exemplified in the art of Plains Cree artist, George Littlechild. Littlechild is a survivor of the Sixties Scoop. He was taken into a foster home at a young age (Littlechild, 2012, p. 13). His art examines the oppression of Indigenous peoples and envisions alternatives through painting and mixed media. He often works with photographs of Indigenous peoples he obtained through extensive archival research to comment and reimagine what these images represent. The painting shown in Figure 2 was created to communicate and subvert his own family history. He indicates "the statement below this piece says it all. Had Mother not attended the residential school, she may not have died so tragically and young, and her five children would not have been raised in foster care or adopted" (Littlechild, 2012, p. 137). He creates a direct link between the residential school system and the Sixties Scoop, and envisions an alternative history where his family would have remained intact. 
While both his parents died before he was able to reconnect with them, Littlechild honours them through his art and reclaims his family history.

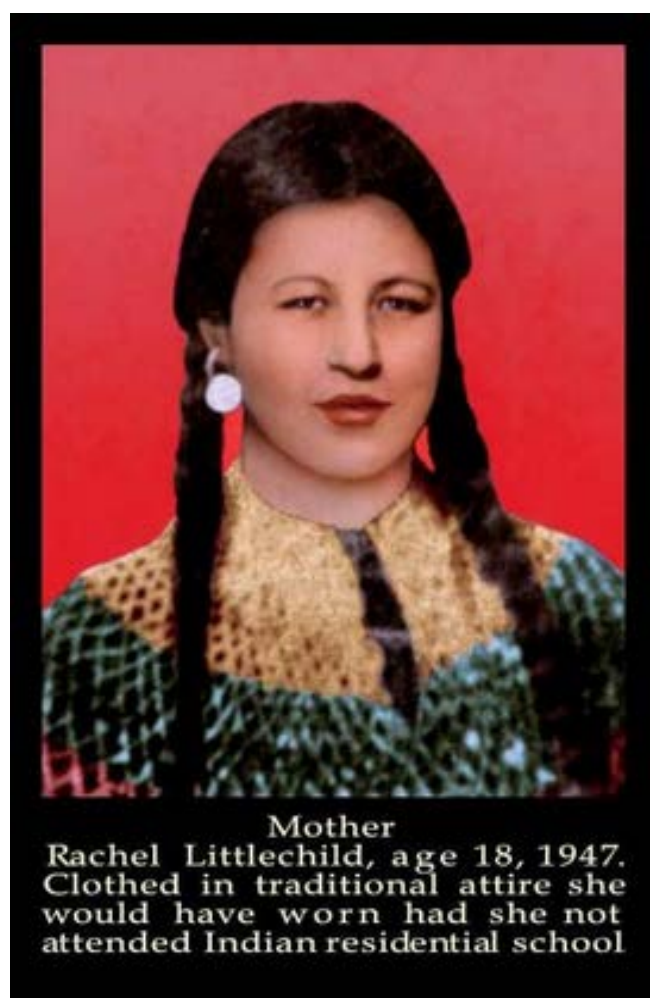

Figure 2. "What could have been" by George Little Child.

Indigenous artists play a central role in theorizing and practicing Indigenous resistance through critical creativity. They are "visionaries leading [Indigenous peoples] to a bright future, to mourning the past in productive ways and to sensuously stunning us in the present” (Driskill et al., 2011, p. 220). By confronting the impacts of settler colonialism, Indigenous artists create a thriving political and cultural life (Amsterdam, 2013, p. 54). Indigenous art reveals and confronts structures of power and fights to realize Indigenous alternatives to settler colonialism (Martineau \& Ritskes, 2014, p. iv). Martineau and Ritskes describe Indigenous art as "fugitive Indigeneity,” actions "to evade capture, resist cooptation, and renew Indigenous life-ways through the creative negation of reductive colonial demarcations of being and sensing (2013, p. 5). 
Navia

\section{Methods}

This project was carried out during 2014 in partnership with the Urban Society for Aboriginal Youth (USAY). USAY is a small non-profit organization that offers programs and services to youth of ages 14 to 30 in Calgary. USAY is entirely composed of Indigenous staff and have conducted programs with youth to challenge racism and connect youth to a larger Indigenous community. Levi First Charger, Outreach worker at USAY and a member of Piikani and Kainai Nations was involved in helping to coordinate the project from the beginning and identifying youth who would like to be involved. A total of 20 youth who had been placed in the child welfare system were formally involved in the project. The average age of youth collaborators was 24 years old. Eleven were female, nine were male and one identified as neither male nor female. Of 20 who took part, 15 disclosed experiences with homelessness. Seven were parents, one was expecting, and four of them have had their children taken into custody by the child welfare system. Five disclosed that they identified with a marginalized sexual identity, or as two-spirit, lesbian, gay, bisexual, trans or queer (2SLGBTQ).

\section{Data Collection}

I will divide the discussion of data collection methods into two sections: interviewing and artistic and creative media. While many of the youth were involved in more than one of these forms of data collection, each form played a distinct role and provided complementary information. Interviews were the foundation of this research, as I sought to hear stories and testimonies in order to develop a better understanding of how they were linked to larger processes. Artistic methods facilitated expression for youth, capturing emotional aspects of their experiences and creating layers of meaning that complemented their narratives. Artistic expression also captivated the interest of many audiences in presentations, exhibits and 
publications.

Interviewing generated most of the data for this research. The interviews had very little structure and involved back and forth discussion. I shared my own experiences and perspectives so that youth would understand my position within the research. My point of view was typically well-received among those I spoke to, and helped to build rapport. For some youth, it helped validate their own critiques of the system, which they would not feel comfortable sharing with many people. Youth were given few instructions of what to talk about at the outset, but rather were told to reflect on their lives and how they think Indigenous people are treated in Canada. As the youth began talking, I would usually only interject to validate what they were saying, discuss something they had said more deeply, or share my own experiences and perspectives including themes that had come up in other interviews. I would try not to change the subject. Ongoing discussions also included topics such as current events, popular culture, and updates about our lives. A typical interview lasted about one hour, but could be as long as three hours. The majority of interviews with youth were audio recorded.

Out of the 20 youth collaborators, 11 were involved in creating and sharing artistic and creative media. Youth were invited to participate in art making as part of the project from the outset, including photography, video, poetry, dance, music or any other forms that were of interest to them. A project outline given to youth provided questions that they could explore through their art. I equipped some of the youth collaborators with supplies when they requested them such as paints, canvases, clay, notebooks and pencils, and lent to some a professional digital camera that was loaned to me for the project. I accompanied two of the youth collaborators to take photographs in the city and at the Tsuu T'ina Nation Pow wow. One youth created a clay sculpture during one of our discussions. The rest of the youth created the art on 
Navia

their own time.

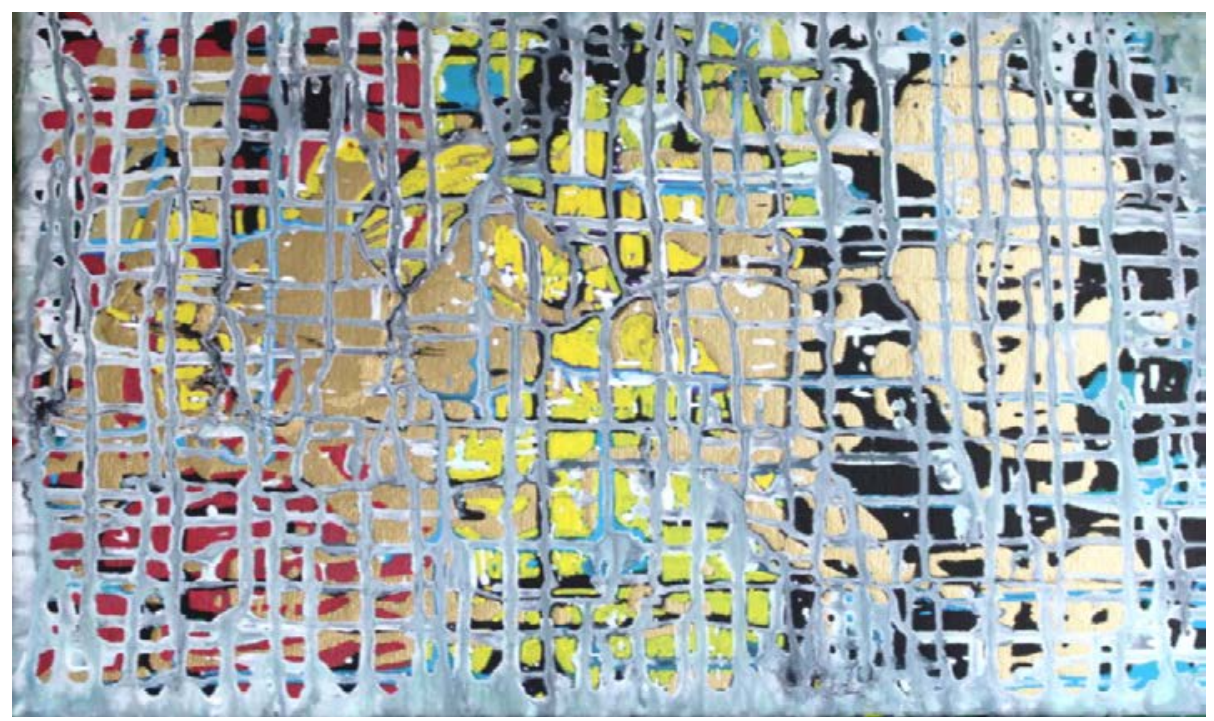

Figure 3. "Four Directions" by Tyler Blackface, youth collaborator.

Art provided an important medium for youth to examine the impact of colonialism in their lives. For example, Tyler Blackface created the painting in Figure 3 during the time of my fieldwork to examine his experience being taken from Siksika to be raised by white foster parents in a predominantly white neighborhood in the city. He wrote the following description to explain the artistic choices he made and their relationship to his personal experiences:

This one represents my feelings while growing up in care. The red, black and yellow are colours from the medicine wheel. The white is supposed to represent a cage and how I felt that I couldn't be who I truly am while growing up 'white' The gold is to represent the illusion of life being "golden" when I was facing numerous problems that I couldn't deal with at that time. - Tyler Blackface, youth collaborator, October 2014.

Blackface uses the colours of the medicine wheel behind a white cage to represent the way his identity was suppressed, leading him to grow up conflicted, confused and without access to his culture and traditions. He chooses these colours as the backdrop to illustrate that his Indigenous identity did not disappear while he was in care, but rather that it was subject to control and regulation. 


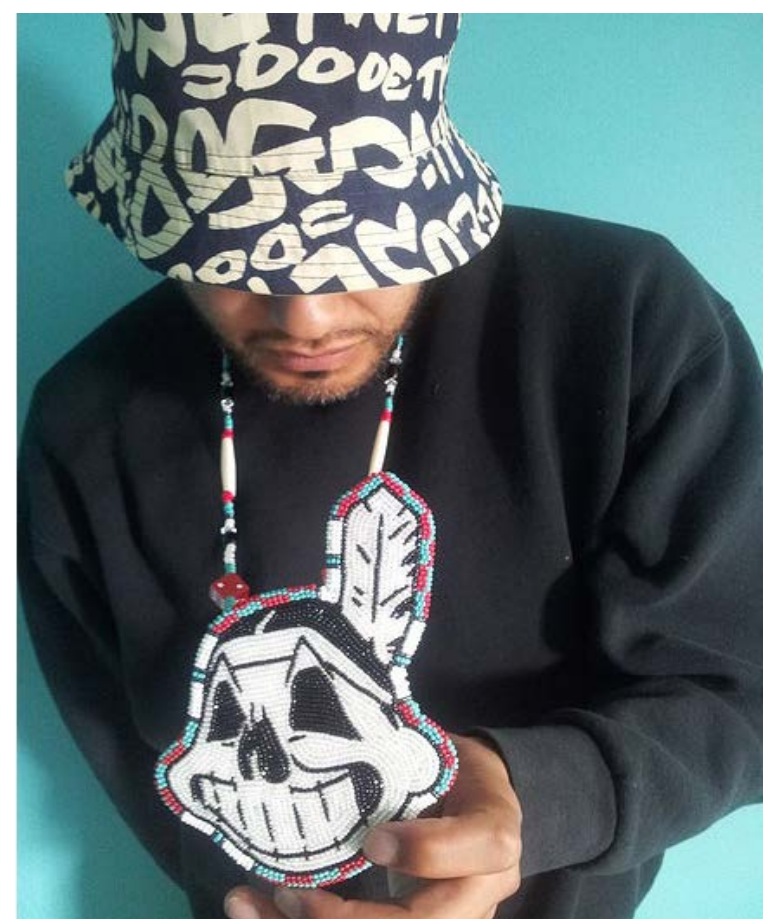

Figure 4. "Kurly's piece” by Angela Gladue, youth collaborator.

Art is also a key mechanism for youth to challenge dominant narratives about Indigenous peoples. The piece in Figure 4 was made by youth collaborator, Angela Gladue for Indigenous graffiti artist Kurly who created the design. She explained "This piece is a satire of the oppression of our people. The Cleveland Indians mascot head, which I turned into a skull” (Calgary, August 2014). A combination of Indigenous beadwork with street style is evident in this piece. They use the piece to make a social commentary on the position of Indigenous peoples in society today and challenge Western-imposed notions of Indigenous identity. They resist the myth of the "dead Indian” an Indigenous person relegated to the past, as well as the objectification of Indigenous peoples as mascots for sports teams.

The final works incorporated in this project included poetry, drawings, photography, paintings, beading, dance, spoken word, rap, and a life map. Youth appreciated having creative modes of expression that provided them with an ability to interpret their life experiences symbolically through artistic media rather than discussing them and to showcase their artistic 
Navia

talents.

\section{Analysis and Dissemination}

The process of making sense of the experiences and products associated with this research has been iterative and was given life as youth collaborators and I began sharing findings in public venues. This was an important aspect of collaboration, as I wanted youth to be integrated into discussions before the written work was completed as a way to enhance the discussion and obtain their feedback. I had anticipated that advocacy would be a key aspect of this project, particularly if youth and Levi First Charger were interested in sharing their perspectives with public audiences. In this section I focus on describing the presentations and events we were involved with in order to stress how this became central to making sense of the experiences discussed in this thesis and supporting youth in presenting on the issues that affect them in public contexts.

The first presentation took place early September 2014, at the Under Western Skies conference at Mount Royal University for a panel on Indigenous law and policy. Rita Henderson, myself, and Tifa Ocampo - one of the youth collaborators - presented to an audience of students, academics and other community members. The goal of the presentation was to provide a brief outline of the research and then give one of the youth an opportunity to share their perspectives on how systemic inequality had shaped their experiences. It was clear that the introduction of a youth collaborator in the presentation was considered outside of the realm of common practice. We were introduced as an academic, a graduate student and an undergraduate. I spoke to the youth after the presentation about this and they laughed, as they had never completed high school and found the idea of post-secondary education to be unattainable. By engaging youth in discussions in environments from which their voices were typically excluded, a different form of 
knowledge was being brought to the forefront. At times youth expressed frustration with trying to "translate" their lived experience to an academic audience, which is why for certain youth presenting at conferences was entirely unappealing. The refusal to be included in academic discussions is also important, and highlights the limits of these settings in promoting understanding of marginalized communities.

Each of the presentations and publications associated with the project has added a layer of analysis. Youth have been able to reflect on their narratives and how they would like to convey them to wider audiences. Each presentation pushed us to think about how to best convey the narratives and artistic expressions created for the project for different audiences and gather feedback. Engagement with theoretical perspectives occurred throughout the project, but was a point of contention for me as I did not want to distance the discussion too far from youth’s narratives to academic discourse that had little meaning to them. Upon finishing my data collection, I felt compelled to just share youth's narratives with little explicit connection to academic analysis. However, after I attended the Researchers and Academics of Colour for Equity conference on “Unsettling Conversations, Unmaking Racisms and Colonialisms” in Edmonton in October 2014, my perspective changed. Several Indigenous scholars presented at that meeting, including Glen Coulthard, Audra Simpson, Maria Campbell and Leanne Simpson. I was inspired by their arguments that related to the experiences of youth who I worked with seamlessly and added a layer of persuasiveness and power to youth narratives. Therefore, I center my academic analysis on relating youth’s everyday experiences to academic discourses, primarily from Indigenous scholars in Critical Race and Indigenous studies about ongoing colonialism and oppression. Youth have generally approved how I have incorporated academic research and theory in presentations and have indicated to me that my analysis complements 
Navia

their stories.

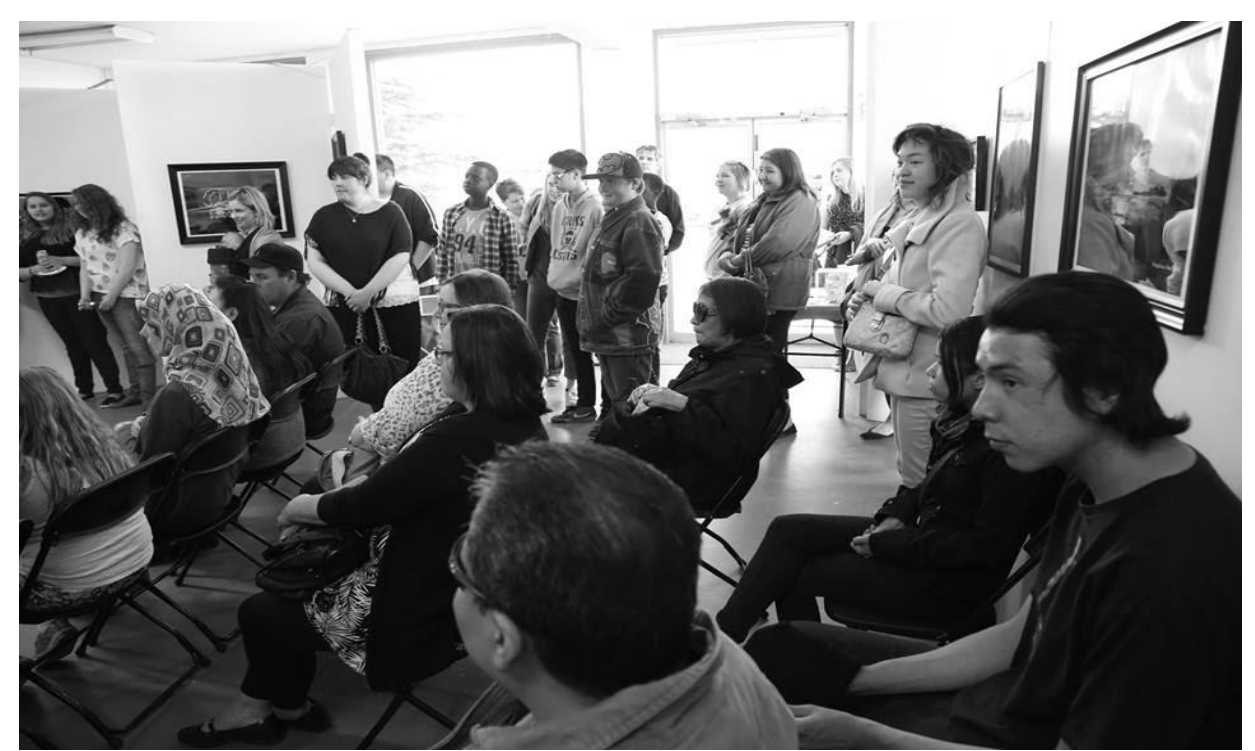

Figure 5. Uncovering Colonial Legacies exhibit opening at This Is My City arts festival, photo by Deloria Many Grey Horses.

\section{Conclusion}

In summary, this research has employed a number of approaches to build relationships and support the generation of knowledge that reflects the experiences of Indigenous youth in child welfare. I collaborated with youth, engaging in interviewing and promoting artistic expression. The anticolonial, collaborative and artistic approaches were each fundamental for the project to take life and enabled many forms of engagement with public audiences.

The collaborative methodology employed in this research is rare in the study of settler colonialism and presents many opportunities for critical renewal. From the outset, a central goal of this project was to integrate youth voices and perspectives into larger academic discussions about colonialism and resistance for Indigenous peoples. This wrongfully presumed that youth were not already participating in these discussions outside of academia. I remember being asked numerous times by individuals in the academy about how I would talk to youth without using academic jargon and high level concepts that they may not identify with such as colonialism. In 
practice, I found that youth could easily relate their personal experiences to historical and political processes using language such as racism, colonialism, stolen land and injustice. The connection between residential schools and the child welfare system seemed clear to most of them due to having witnessed the impact of one and having experienced the other. All participants provided concrete examples of how these mechanisms play a role in their lives, bringing insight into different forms of violence and resistance that has not been paid due attention in academic and practitioner contexts. By placing emphasis on how youth are already engaged in analyzing their culture, youth agency in the process of sense-making is brought to the forefront (see also Spring \& Fox in this volume).

The focus on art, expression, and resistance to colonialism through collaboration was an effective way to engage with youth and create opportunities for solidarity. This project serves as a testament that productive alliances between groups, particularly those who share experiences with racism and displacement are possible. It created opportunities for supporting anticolonial struggles and building coalitions among racialized peoples. When meeting youth, I would share some of my personal experiences with racism in Canada and my reflections on witnessing injustice while doing research at the mental health agency. This approach enabled critiques of the child welfare system and was highly effective in creating discussion that youth wanted to participate in.

The approach presented here presents many challenges to anthropological ethics and how to envision mutually beneficial research relationships. While my leadership has brought many people together in meaningful ways, this was not a project conceived within Indigenous communities and at times reproduced colonizing tendencies within research. Nevertheless, I believe that there are many possibilities emerging from this research to promote future alliances 
Navia

through critical dialogue, relationship building and support. Future work should continue to address state violence experienced by racialized peoples but also focus on establishing more equitable forms of collaboration and enhancing opportunities for racialized groups to work together, create and advance anti-colonial struggles. 


\section{References}

Ahmed, S. (2000). Strange encounters: Embodied others in post-coloniality. New York, NY: Routledge.

Amsterdam, L. J. (2013). All the eagles and the ravens in the House Say Yeah: (Ab)Original hiphop, heritage, and love. American Indian Culture and Research Journal, 37(2), 53-72

Asad, T. (1973). Anthropology and the colonial encounter (London, Ithaca Press). Assembly of First Nations (2006). Leadership action plan on First Nations Child Welfare. Ottawa, ON: Assembly of First Nations.

Beavon, D. J., Voyageur, C. J., \& Newhouse, D. (Eds,; 2005). Hidden in plain sight: contributions of Aboriginal peoples to Canadian identity and culture (Vol. 1). Toronto, ON: University of Toronto Press.

Carriere, J. (2010). Aski Awasis/Children of the earth: First Peoples speaking on adoption. Blackpoint, NS: Fernwood Publishing

Chapman, M. V., Wall, A., \& Barth, R. P. (2004). Children's voices: The perceptions of children in foster care. American Journal of Orthopsychiatry,74(3), 293-304.

Comaroff, J. \& Comaroff, J. (2003). Ethnography on an awkward scale Postcolonial anthropology and the violence of abstraction. Ethnography, 4(2), 147-179.

Cruikshank, J. (2000). Social Life of Stories: Narrative and Knowledge in the Yukon Territory. Vancouver, BC: UBC Press.

Deloria, V. (1988) Custer died for your sins: An Indian manifesto. Norman, OK: University of Oklahoma Press.

Driskill, Q.L., Finley, C., Gilley, B.J., \& Morgensen, S. (Eds.; 2011). Queer Indigenous studies: Critical interventions in theory, politics, and literature. Tucson, AZ: The University of Arizona Press.

Gaztambide-Fernández, R. A. (2012). Decolonization and the pedagogy of solidarity. Decolonization: Indigeneity, Education \& Society, 1(1).

Gray, R. (2011). Visualizing pedagogy and power with Urban Native Youth: Exposing the legacy of the Indian Residential School system. Canadian Journal of Native Education, 34(1), 9-103.

Hedican, E. J. (2008). Applied Anthropology in Canada: Understanding Aboriginal Issues. Toronto, ON: University of Toronto Press.

Hill, G. (2013). Afterward: Looking back to Sakahàn. In G. Hill, C. Hopkins, \& C. Lalonde (Eds.), Sakahàn: International Indigenous art. Ottawa, ON: National Gallery of Canada. 
Hunt, S. (2014). Ontologies of Indigeneity: the politics of embodying a concept. Cultural geographies, 21(1), 27-32.

Jahnke, H. T. \& Gillies, A. (2012). Indigenous Innovations in Qualitative Research Method: Investigating the Private World of Family Life. International Journal of Qualitative Methods, 11(4).

Kane, E. (2010). Trickster: An anthropological memoir. University of Toronto Press.

Kovach, M. E. (2010). Indigenous methodologies: Characteristics, conversations, and contexts. Toronto, ON: University of Toronto Press.

Lassiter, L. E. (2005). The Chicago guide to collaborative ethnography. Chicago, IL: University of Chicago Press.

Littlechild, G. (2012). George Littlechild: The Spirit Giggles Within. Victoria, BC: Heritage House Publishing Co.

Marcus, G. E. \& Fischer, M. M. (1999). Anthropology as cultural critique: An experimental moment in the human sciences. Chicago, IL: University of Chicago Press.

Martineau, J. \& Ritskes, E. (2014). Fugitive indigeneity: Reclaiming the terrain of decolonial struggle through Indigenous art. Decolonization: Indigeneity, Education \& Society, 3(1).

Menzies, P. (2008). Developing an Aboriginal healing model for intergenerational trauma. International Journal of Health Promotion and Education, 46(2), 41-48

Mitchell, L. M. (2006). Child-centered? Thinking critically about children's drawings as a visual research methods. Visual Anthropology Review, 22(1), 60-73.

Mutua, K. \& Swadener, B. B. (Eds.). (2004). Decolonizing research in cross-cultural contexts: Critical personal narratives. Albany, NY: SUNY press.

Reid, M. (2005). First Nations women workers' speak, write and research back: Child welfare and decolonizing stories. First Peoples Child \& Family Review, 2(1), 21-40.

Simpson, A. (2014). Mohawk interruptus: Political life across the borders of settler states. Durham, NC: Duke University Press.

Simpson, A. (2011). On ethnographic refusal: indigeneity, 'voice’ and colonial citizenship. Junctures: The Journal for Thematic Dialogue, 9, 67-80.

Sium, A. \& Ritskes, E. (2013). Speaking truth to power: Indigenous storytelling as an act of living resistance. Decolonization: Indigeneity, Education \& Society, 2(1), I-X.

Smith, A. (2006). Heteropatriarchy and the three pillars of white supremacy: Rethinking women of color organizing. In INCITE! Women of Color Against Violence, Color of violence: The INCITE! Anthology (pp. 66-73). Cambridge, MA: South End Press 
Smith, L. T. (1999). Decolonizing methodologies: Research and indigenous peoples. Zed books.

Spivak, G. (2003). Subaltern studies. Deconstruction: Critical Concepts in Literary and Cultural Studies, 4, (Vol. 220).

Tuck, E. \& Yang, K. W. (2012). Decolonization is not a metaphor. Decolonization: Indigeneity, Education \& Society, 1(1), 1-40.

Walia, H. (2013). Undoing Border Imperialism. Oakland, CA: AK Press, 314.

Wilson, S. (2008). Research is ceremony: Indigenous research methods. Winnipeg, MB: Fernwood Pub.

Wolf, E. R. (2010). Europe and the People without History. Oakland, CA: University of California Press.

Wong, R. (2008). Decolonizasian: Reading Asian and First Nations relations in literature. Canadian Literature, 199, 158-180. 